\title{
LA SUPREMA CORTE Y EL PODER CONSTITUYENTE CONSTITUIDO. HACIA LA DEFENSA DEL NÚCLEO INTANGIBLE DE LA CONSTITUCIÓN
}

\author{
THE SUPREME COURT AND THE CONSTITUTED \\ CONSTITUENT POWER. TOWARD THE DEFENSE \\ OF THE INTANGIBLE NUCLEUS OF THE CONSTITUTION
}

\section{Francisco VÁZQUEZ GóMEZ BISOGNO}

RESUMEN: La defensa del núcleo intangible de la Constitución, y con ello el sometimiento del poder constituyente constituido a los medios de control constitucional, son las premisas fundamentales que el autor maneja en este artículo. Para demostrar su hipótesis, parte del debate generado por la reforma electoral aprobada en 2007, misma que ha sido cuestionada por un amplio sector de la doctrina, como una reforma constitucional que violentó los postes fijados por el constitucionalismo contemporáneo, en concreto, el derecho fundamental a la libertad de expresión. Más allá de este paradigmático caso, el autor se adentra a los conceptos básicos de la teoría constitucional, para demostrar que, si en verdad queremos consolidar en México un Estado constitucional y democrático de derecho, debemos comenzar por reconocer que en toda Constitución existe un núcleo intangible, el cual debe ser defendido de todos los poderes constituidos, incluido el órgano que tiene facultades para reformar la ley fundamental.

Palabras clave: núcleo intangible, poder constituyente constituido, control constitucional, imperio del derecho.
ABSTRACT: On defending the intangible nucleus of the Constitution, the constituted constituent power must be submitted to specific constitutional means of control, is the fundamental premise which the author is supporting along this article. To prove his hypothesis, the author starts with the debate generated by the 2007 approved electoral reform, the same that has been questioned by a wide doctrine sector of our society, considering such a constitutional reform as one which went far beyond the limits established by the contemporary constitutionalism, in particular, the fundamental right of free expression. And beyond that paradigmatic case, the author goes deeper into the basic principles of the constitutional theory to prove that, if we actually want to consolidate Mexico as an constitutional and democratic state of law, we must begin by recognizing that within every constitution there is an intangible nucleus, which must be defended of all constituted powers at any given moment, including the organ which wears faculties to reform the fundamental law.

Descriptors: Intangible Nucleus, Constituted Constituent Power, Constitutional Control, Rule of Law. 


\section{PlanteAmiento GENERAL}

Es evidente, en efecto, que podríamos diferenciar los bienes según una doble acepción: unos por sí mismos, otros por razón de aquéllos. Separando, pues, los bienes esenciales de los bienes útiles... ${ }^{1}$

ARISTÓTELES

Hace algún tiempo escuché de alguien decir que todas las cosas tienen un núcleo, una porción esencial e intangible, y que además ahí se contiene la información más importante de cada existencia.

Pasando por la más simple de las existencias - como lo es la de una diminuta célula - hasta la más compleja — como lo es la existencia del universo- - el ser humano, gracias al sentido común y al maravilloso deseo cognoscitivo que posee, se ha visto predispuesto a distinguir, dividir, comparar, contrastar y analizar, todo ello, encaminado a comprender y entender — en la mayor extensión posible — la realidad que le rodea.

Se ha afirmado que "al hombre de poca cultura le basta con percibir una diferencia entre dos seres para inmediatamente oponerlos; pero los más experimentados conocen el arte de distinguir sin separar, siempre que no haya razones esenciales que justifiquen la contraposición". ${ }^{2}$

De esta forma, si partimos de la base que toda existencia tiene un núcleo, lo cierto es que no todo lo existente es núcleo, es decir, deben existir componentes de otra categoría.

Así, lo distinto o contrapuesto al núcleo es la periferia, y la "distinción entre núcleo/periferia es tan tradicional en los estudios gramaticales como la de Aristóteles entre sustancia y accidentes...". Por tanto, analógicamente se puede afirmar que si hablamos de núcleo, estamos haciendo

1 Aristóteles, Ética nicomaquea, 17a. ed., trad. de Antonio Gómez Robledo, México, Porrúa, 1998, p. 4.

2 Reale, Miguel, Introducción al derecho, Madrid, Ediciones Pirámide, s. a., p. 51.

3 Escribano, José Luis, “Reflexiones acerca del concepto de 'núcleo' en la gramática tagmémica”, Archivum, Oviedo, año 1979-1980, núm. 29-30, p. 226, http://dialnet.unirioja.es/servlet/listaarticulos?tipo_busqueda $=$ EJEMPLAR\&revista_busqueda $=$ $158 \&$ clave_busqueda $=14418$ 
referencia a lo sustancial, y si hablamos de periferia, haremos referencia a lo accidental. Sin duda, tal afirmación invita a la reflexión.

Es por lo anterior que, so pretexto de la debatida reforma constitucional que - en materia electoral - fuera aprobada por el poder constituyente constituido ${ }^{4}$ del Estado mexicano, hemos querido adentrarnos a la distinción entre lo nuclear/periférico, lo sustancial/accidental y lo esencial/no esencial de la Constitución Política de los Estados Unidos Mexicanos a efecto de determinar si, ante tal distinción, los contenidos constitucionales deben o pueden ser tratados de la misma forma por aquel poder.

La reforma constitucional mencionada, no sólo invita a la reflexión en torno a las ideas que se han planteado, sino que además su análisis será el medio idóneo para abordar un tema de alto contenido teórico que sin duda posee muy importantes consecuencias prácticas.

Comencemos por recordar que el 13 de noviembre de 2007 se publicó en el Diario Oficial de la Federación el decreto mediante el cual se reformaron diversos artículos de la Constitución Política de los Estados Unidos Mexicanos, a efecto de regular el sistema electoral mexicano, tomando en consideración las experiencias de la controvertida elección federal de julio de 2006.

De esta forma, el proceso electoral federal 2008-2009, que iniciara formalmente el 3 de octubre de $2008^{5}$ sería una de las primeras ocasiones en donde se pondrían a prueba — derivado de su aplicación — las modificaciones constitucionales y legales correspondientes. Por ello, resulta importante reflexionar en torno a los alcances, efectos y repercusiones de la reforma constitucional de mérito, teniendo presente que quizá dicha

4 Debido a que la doctrina ha denominado de diversas maneras al órgano facultado para enmendar a la Constitución, y sin que nosotros nos pronunciemos respecto de cuál es el concepto más adecuado debido a que no es el objetivo de la presente investigación, a lo largo del presente estudio se hará referencia de manera indistinta a los conceptos de "poder constituyente constituido", "poder constituyente permanente", "poder revisor de la Constitución", "poder reformador de la Constitución", "órgano reformador de la Constitución", "poder de revisión de la Constitución", "poder de reforma", etcétera, entendiéndose por todos ellos el órgano facultado para llevar a cabo reformas y enmiendas al texto constitucional.

5 De acuerdo con el artículo 210, inciso 3, del Código Federal de Instituciones y Procedimientos Electorales: "La etapa de preparación de la elección se inicia con la primera sesión que el Consejo General del Instituto celebre durante la primera semana de octubre del año previo al en que deban realizarse las elecciones federales ordinarias y concluye al iniciarse la jornada electoral". 
prueba habrá de acontecer integralmente en la elección presidencial de 2012.

Esta reforma constitucional tiene como finalidad - a decir de sus impulsores - actualizar al sistema electoral mexicano de acuerdo con las nuevas realidades que lo pusieron en una difícil prueba en las elecciones federales de 2006.

A efecto de que determinemos con exactitud cuál es la litis generada en el caso concreto, debemos señalar que los detractores de la reforma han venido esgrimiendo que suprime por completo la libertad de expresión - concretamente en materia político-electoral- contenida en el artículo 6o. constitucional al adicionar al artículo 41 lo siguiente:

Ninguna persona física o moral, sea a título propio o por cuenta de terceros, podrá contratar propaganda en radio y televisión dirigida a influir en las preferencias electorales de los ciudadanos ni a favor o en contra de partidos políticos y candidatos a cargos de elección popular.

Para muchas empresas y organizaciones de la sociedad civil no es tan clara la finalidad que persiguieron sus impulsores, ya que observan en la reforma constitucional de mérito, una evidente violación a diversos derechos fundamentales reconocidos por nuestra carta magna. tado que

El propio Consejo Coordinador Empresarial (CCE) ha manifes-

esta adición implica que únicamente los partidos políticos pueden ejercer el derecho de libertad de expresión, dejando amordazados a ciudadanos y/o asociaciones civiles incluso para llamar al ejercicio de un voto informado, libre, razonado y secreto. La libre manifestación de las ideas es un elemento fundamental para la formación de opinión pública y, por ende, un componente necesario para el funcionamiento de una democracia representativa. ${ }^{6}$

La postura anterior - dicho sea de paso- resulta congruente con lo que al respecto han señalado algunos organismos internacionales. Para nadie es desconocido que hoy en día, los operadores jurídicos no sólo debemos atender a las normas positivas nacionales para resolver los con-

6 Consejo Coordinador Empresarial, Comunicado de Prensa, 5 de diciembre de 2007, http://www.cce.org. $m x / N R /$ rdonlyres/DD82638D-E6F7-4538-84F8-C08B07DB0B03/ 1897/amparo_5dic07.pdf 
flictos jurídicos que se nos plantean. Por el contrario, hoy más que nunca estamos ante la concretización de un sistema jurídico flexible que permite la inclusión de principios derivados de derecho, jurisprudencia y doctrina internacionales.

Así, por ejemplo, si en el presente caso nos encontramos ante una tensión entre el derecho a la libertad de expresión y el derecho de los pueblos a su libre autodeterminación (en el cual debe incluirse la libertad que tienen las naciones para definir las reglas básicas para la celebración de las elecciones que permitirán integrar a los órganos representativos y democráticos del Estado), un criterio al que podemos atender para ir vislumbrando la litis en la que encuentra sustento el presente trabajo, es el señalado por la Corte Interamericana de los Derechos Humanos en un caso en el cual se avocó al análisis del papel que debe jugar la libertad de expresión en los procesos electorales.

Al respecto, la Corte Interamericana de Derechos Humanos ha señalado lo siguiente:

90. El Tribunal considera indispensable que se proteja y garantice el ejercicio de la libertad de expresión en el debate político que precede a las elecciones de las autoridades estatales que gobernarán un Estado... El debate democrático implica que se permita la circulación libre de ideas e información respecto de los candidatos y sus partidos políticos por parte de los medios de comunicación, de los propios candidatos y de cualquier persona que desee expresar su opinión o brindar información. Es preciso que todos puedan cuestionar e indagar sobre la capacidad e idoneidad de los candidatos, así como disentir y confrontar sus propuestas, ideas y opiniones de manera que los electores puedan formar su criterio para votar. En este sentido, el ejercicio de los derechos políticos y la libertad de pensamiento y de expresión se encuentran íntimamente ligados y se fortalecen entre sí. ${ }^{7}$

Bajo esta tesitura, el problema de la reforma electoral mexicana de 2007 se materializa en que prohíbe que los particulares puedan ejercitar su derecho fundamental a la libertad de expresión — mediante los medios de comunicación - durante los procesos electorales, lo cual, según los órganos internacionales, no es justificable debido a que el ejercicio de

7 Corte Interamericana de Derechos Humanos. Caso Ricardo Canese vs. Paraguay, sentencia del 31 de agosto de 2004. 
los derechos políticos y la libertad de pensamiento y de expresión se encuentran íntimamente ligados y se fortalecen entre sí.

Es por ello que 22 días después de la publicación de la reforma aprobada por el poder revisor de la Constitución, es decir, el 5 de diciembre de 2007 ,

el pleno del Consejo Coordinador Empresarial (CCE) se amparó en contra de la reforma electoral por considerar que ésta viola las garantías constitucionales de la libertad de expresión en México y atenta contra los derechos internacionales de los individuos de ejercer plenamente sus ideas y de tomar parte en la vida política de un país. ${ }^{8}$

Sin duda alguna desde la promoción de este juicio de amparo, procedimiento de control constitucional más recurrido dentro del sistema jurídico mexicano, y que por lo tanto forma parte del derecho procesal constitucional de nuestro país ${ }^{9}$, no se hicieron esperar las voces de los legisladores que aprobaron dicha reforma, calificando de absurdo e improcedente el juicio planteado por el CCE. Así lo señalaba la prensa nacional del 7 de diciembre de 2007:

es una vacilada, resumió el senador panista Santiago Creel, mientras el perredista Carlos Navarrete comentó que seguramente el CCE fue asesorado por un pasante de derecho que reprobó, porque todo mundo sabe que en materia electoral no hay amparos contra disposiciones de la Constitución. ${ }^{10}$

8 La Crónica de Hoy, 6 de diciembre de 2007, http://www.cronica.com.mx/ nota. php?id_nota $=336557$

9 Sólo basta con hacer referencia a algunas ideas que han generado grandes juristas de nuestra época, en el sentido de que "el derecho procesal constitucional constituye la rama más reciente de la ciencia procesal, que se encarga esencialmente del estudio sistemático de las garantías constitucionales en su sentido contemporáneo, es decir, esta disciplina comprende el análisis de aquellos instrumentos predominantemente procesales que están dirigidos a la reintegración del orden constitucional cuando el mismo ha sido desconocido o violado por los órganos del poder". Véase Ferrer Mac-Gregor, Eduardo, "Aportaciones de Héctor Fix-Zamudio al derecho procesal constitucional”, en Ferrer Mac-Gregor, Eduardo (coord.), Derecho procesal constitucional, 5a. ed., México, Porrúa-Colegio de Secretarios de la Suprema Corte de Justicia de la Nación, 2006, t. I, p. 216.

10 La Jornada, 7 de diciembre de 2007, http://www.jornada.unam.mx/2007/12/ 07/ index.php?section $=$ politica\&article $=008 n 1$ pol 
Lo cierto era - hasta esos momentos - que a unos días de la presentación de la demanda de amparo formulada por el CCE, "el juez David Cortés dentro del expediente 1566/2007 ordenó que se notificara de forma personal a los quejosos la notoria improcedencia del recurso que... interpuso el CCE contra las reformas publicadas el 13 de noviembre pasado en el Diario Oficial de la Federación". ${ }^{11}$

En este sentido, el mismo 7 de diciembre de 2007, el CCE señalaba que

este escenario era previsible si consideramos la tendencia que existe por parte de los jueces federales de primera instancia, de abstenerse de conocer formalmente demandas de esta complejidad, dejando que sean instancias de mayor nivel las que se pronuncien al respecto, por lo que presumimos terminará por resolverse en la SCJN. ${ }^{12}$

Así pues, sabíamos también que la Suprema Corte de Justicia de la Nación (SCJN) —en su calidad de tribunal constitucional— ${ }^{13}$ sería el órgano que en última instancia resolvería estos puntos en concreto, ya que algunos de sus integrantes consideran que por ser un tema relevante para

11 El Economista, 7 de diciembre de 2007, http://www.eleconomista.com.mx/articu los/2007-12-07-50849

12 Consejo Coordinador Empresarial, Comunicado de Prensa, 7 de diciembre de 2007, http://www.cce.org.mx

13 Pero, ¿qué debemos entender por tribunal constitucional? La doctrina a este respecto es muy clara al afirmar que existen dos formas en cómo debe mirarse a este tipo de órganos: desde una perspectiva formal, o bien, desde un enfoque material. "Desde una perspectiva formal, que corresponde a la concepción tradicional, es aquel órgano creado para conocer especial y exclusivamente de los conflictos constitucionales, situado fuera del aparato jurisdiccional ordinario e independiente tanto de éste como de los poderes públicos. Conforme a esta concepción, las cortes o tribunales supremos pueden ser jurisdicciones constitucionales pero no son, en estricto sentido, tribunales constitucionales. Esta noción se identifica fundamentalmente con el modelo europeo de tribunal constitucional. Una noción moderna y más amplia que corresponde a su enfoque material, entiende por tribunal constitucional al órgano jurisdiccional de mayor jerarquía que posee la función esencial o exclusiva de establecer la interpretación final de las disposiciones de carácter fundamental. En esta concepción se encuentran varias cortes o tribunales supremos de América Latina, donde podemos ubicar a la Suprema Corte de Justicia de México... que se ha convertido materialmente en un tribunal constitucional". Véase Ferrer Mac-Gregor, Eduardo, "Los tribunales constitucionales y la Suprema Corte", en Ferrer MacGregor, Eduardo (coord.), Derecho procesal onstitucional, cit., nota 9, t. I, p. 242. 
el país se debería analizar la posición empresarial, la cual era apoyada por un grupo de intelectuales. Así, el Pleno de ese alto tribunal podría y debería pronunciarse al respecto.

De esta forma, la SCJN se pronunció en torno a múltiples amparos promovidos en contra de la reforma constitucional cuestionada. En algunos casos desechó tales recursos, en otros señalaría que eran improcedentes, pero en otros resolvería devolver el asunto a los jueces de distrito que conocieron de los amparos indirectos, a fin de que se revisara la postura asumida por tales juzgadores, lo cual, sin duda alguna, dejaría abierta la posibilidad de que esos juicios regresaran nuevamente al conocimiento del máximo tribunal mexicano. ${ }^{14}$

Es por ello que hemos considerado de suma importancia que podamos advertir — de acuerdo con un análisis de los conceptos básicos de la teoría constitucional - que si en verdad queremos consolidar un Estado constitucional y democrático de derecho, debemos comenzar por reconocer que en toda Constitución existe un núcleo intangible, el cual debe ser defendido de todos los poderes constituidos, incluido el poder constituyente constituido. Con este análisis como premisa, podremos establecer cuál es el estatus de la doctrina jurisprudencial ${ }^{15}$ que ha desarrollado la Suprema Corte de Justicia de la Nación ante casos en los que se han impugnado reformas a la Constitución, es decir, cuál ha sido la

14 Concretamente nos referimos al amparo en revisión 186/2008 promovido por el Centro Empresarial de Jalisco, Sindicato Patronal, contra actos del Congreso de la Unión y otras autoridades, consistentes en la expedición y aplicación del decreto por el que se reformaron los artículos 6o., 41, 85, 99, 108, 116 y 122, adicionó el artículo 134 y derogó el párrafo tercero del artículo 97 de la Constitución Política de los Estados Unidos Mexicanos, publicado en el Diario Oficial de la Federación del 13 de noviembre de 2007.

15 Entiéndase por doctrina jurisprudencial a las resoluciones judiciales referenciales que, pudiendo ser o no formalmente jurisprudencia, en el fondo de los fallos se observa el análisis de un mismo problema jurídico que permite analizar la manera en que se va desarrollando un criterio jurídico, razón por la cual se les considera "doctrina" puesto que constituyen opiniones cuya validez es de naturaleza estadística: la repetición constante. Así, por ejemplo, Rodolfo Luis Vigo al analizar una nómina de argumentos, hace referencia al argumento jurisprudencial, señalando que es aquel que se apoya en decisiones no obligatorias porque en el supuesto de que la tuvieran se estaría en presencia del argumento autoritativo, no jurisprudencial (véase Vigo, Rodolfo Luis, "La argumentación constitucional", en Báez Silva, Carlos et al. (coords.), Interpretación, argumentación y trabajo judicial, México, Porrúa-Facultad de Derecho UNAM-Universidad Panamericana, 2009, p. 234). 
relación entre el tribunal constitucional mexicano con el poder revisor de la Constitución.

\author{
II. EL RULE OF LAW Y EL SOMETIMIENTO DEL PODER \\ CONSTITUYENTE CONSTITUIDO AL IMPERIO DEL DERECHO
}

...para la debida defensa de la libertad no basta con el concepto racional normativo puramente formalista propio del mundo liberal burgués, sino que será necesario operar con un concepto material de Constitución en el que determinados ámbitos del texto constitucional resulten inmodificables... ${ }^{16}$

Pedro de Vega García

Si lo que pretendemos es determinar la conveniencia o no de que el poder revisor de la Constitución y, por lo tanto, las reformas a la ley fundamental puedan ser objeto de control constitucional formal o material, ${ }^{17}$ nos parece que un tema que no puede dejar de abordarse para conseguir el objetivo que nos hemos trazado, es el relativo a qué se ha venido entendiendo por Estado de derecho y su diferencia con la idea original inglesa de Rule of Law.

16 Vega García, Pedro de, "La reforma constitucional como defensa de la Constitución y de la democracia”, en Valadés, Diego y Carbonell, Miguel (coords.), El Estado constitucional contemporáneo. Culturas y sistemas jurídicos comparados, México, UNAM, Instituto de Investigaciones Jurídicas, 2006, t. II, p. 349.

17 Entiéndase por control constitucional formal aquel ejercicio que se refiere a revisar si las normas impugnadas cumplen o no con las normas sobre la producción jurídica, es decir, si cumplen con aquellas normas constitucionales que establecen los procedimientos de creación, modificación y reforma de las normas jurídicas que componen un sistema normativo, a diferencia del control constitucional material, a través del cual, los jueces constitucionales resuelven la posible contradicción de una norma con los valores y principios que se establecen en las cartas magnas. Véase Carbonell, Miguel, Constitución, reforma constitucional y fuentes del derecho en México, México, Porrúa, 2000, pp. 15-18. 
Lo anterior resulta importante ya que no podemos perder de vista que toda garantía constitucional, es decir, cualquier medio de control constitucional encuentra su justificación, eficacia y proyección en el contenido y alcance que le demos al concepto de Rule of Law.

El Rule of Law debe ser entendido - siguiendo los planteamientos de Antonio Carlos Pereira Menaut - como imperio del derecho, que no es otra cosa sino un procedimiento invento del constitucionalismo, a través del cual el derecho debe frenar al poder.

Así pues, esta idea constitucional surge para impedir que el príncipe siga configurándose en legibus solutus ${ }^{18}$ y iure solutus,${ }^{19}$ es decir, que el monarca sea el único legislador y creador del derecho para evitar con ello la arbitrariedad y generar el comienzo de un largo trayecto en la historia

18 La expresión viene de un texto del Digesto "princeps legibus solutus est" (Dig. 1, $3,31)$ que significa que el príncipe no esté ligado a las leyes o que se encuentre por encima de ellas. Ejemplos de las consecuencias de este "principio", mismo que dio sustento a las teorías estatistas del absolutismo, pueden encontrarse muchos a lo largo de la historia, por lo que sólo para mencionar uno de los más conocidos y polémicos, citaremos el caso de Enrique VIII, quien no perdía la oportunidad de imponer su propio criterio al Parlamento inglés, órgano que en 1533 aprobó una ley que declaró nulo el matrimonio de Enrique VIII con su primera mujer Catalina de Aragón, y en 1536 aprobó una nueva norma en virtud de la cual anuló igualmente el segundo matrimonio del monarca con Ana Bolena. Con este episodio de la historia inglesa, no sólo se deja ver el peligro que genera para la organización misma del Estado, reconocer que un órgano estatal pueda configurarse como legibus solutus, sino que este tipo de esquemas son una de las causas más importantes para la generación de arbitrariedades, y por lo tanto, para la violación de derechos fundamentales. Así lo señala Bruno Aguilera Barchet, profesor de Historia del derecho contemporáneo en la Universidad Rey Juan Carlos en España, manifestando que la ley expedida por el Parlamento inglés en 1536 estipulaba también que cualquier persona que considerase válido el matrimonio entre Enrique VIII y Ana Bolena sería condenado como autor de un delito de traición. Véase la página de Internet del Instituto de Estudios Jurídicos Internacionales: http://www.ieji.es/3_Monarquia_absoluta.pdf

19 De acuerdo con el profesor de la Universidad Católica Argentina, Gustavo Irrazábal, el concepto de iure solutus se construye a partir de los mismos fundamentos teóricos que sustentan el concepto de legibus solutus, pero es llevado al extremo toda vez que "el rey era considerado legibus solutus porque se le atribuía la facultad de cambiar la ley cuando lo considerara oportuno, pero no iure solutus, pues estaba sometido al derecho natural y debía responder de ello ante Dios", por lo que la diferencia entre ambos conceptos radica en que el primero, aún se encontraba sometido y limitado por el derecho natural, mientras que el segundo ya no encontraba límite alguno a su función creadora o productora de derecho. Véase Irrazábal, Gustavo, "La libertad política y la DSI", p. 3, http://www2.uca.edu.ar/uca/common/grupo24/files/Irraz-bal.pdf 
de la humanidad por limitar y estructurar el poder mediante la protección de los derechos fundamentales y una adecuada división de poderes. No por nada,

...un Estado puede llamarse constitucional, o provisto de Constitución [señala Guastini] si y sólo si, satisface dos condiciones (disyuntivamente necesarias y conjuntivalmente suficientes): 1) por un lado, que estén garantizados los derechos de los ciudadanos en sus relaciones con el Estado, y 2) por otro, que los poderes del Estado estén divididos y separados... ${ }^{20}$

De ahí que el afirmar que el poder revisor de la Constitución, aun cuando debe ser considerado un poder constituido, no pueda ser sujeto de control constitucional — ni formal ni material - pareciera acercarnos a aquellas épocas de los Estados medievales en donde los monarcas dictaban el derecho con cada palabra que pronunciaran, fueran éstas razonables o no, justas o injustas, coherentes o incoherentes. Simplemente eran derecho porque provenían del monarca, es decir, del leviatán hobbesiano. ${ }^{21}$

Por lo hasta ahora mencionado, pareciera que las garantías constitucionales o medios de control de la constitucionalidad en relación con el Rule of Law configuran una simbiosis constitucional ${ }^{22}$ de suma importancia, ya que aquéllas surgen para tutelar los derechos fundamentales que fueron el principal objetivo de los grandes movimientos revolucionarios (la revolución gloriosa en Inglaterra, la independencia en Estados Unidos y la revolución en Francia) que lucharon en contra de una soberanía y potestad legislativa ilimitada. Es decir, sin tales garantías o medios de

20 Guastini, Riccardo, Estudios de teoría constitucional, México, Fontamara-UNAM, Instituto de Investigaciones Jurídicas, 2001, p. 31.

21 De hecho Thomas Hobbes señalará que la ley civil (el derecho creado por el soberano) "es, para cada súbdito, aquellas reglas que el Estado le ha ordenado de palabra o por escrito o con otros signos suficientes de la voluntad, para que las utilice en distinguir lo justo de lo injusto, es decir, para establecer lo que es contrario y lo que no es contrario a la ley... no pudiendo ser reputado injusto lo que no sea contrario a ninguna ley", es decir, es el Estado el que "iluminará" a los gobernados — a través de sus leyes — para que éstos sean capaces de distinguir lo justo de lo injusto. Véase Hobbes, Thomas, Leviatán, cap. XXVI, p. 108, http://www.scribd.com/doc/2346332/Hobbes-Leviatan

22 "Simbiosis", asociación de individuos animales o vegetales de diferentes especies, sobre todo si los simbiontes sacan provecho de la vida en común. Véase Diccionario de la Lengua Española, 22a. ed., Real Academia Española, http://buscon.rae.es/draeI/ 
control sería imposible concretar el sometimiento del poder al derecho, razón por la cual, como ya hemos afirmado, hoy en día sería ilusorio pensar en el establecimiento de un Estado constitucional de derecho sin la existencia de medios de control de la constitucionalidad.

Aunado a ello, si analizamos cuáles son las características del imperio del derecho, nos daremos cuenta que para su actualización, es requisito indispensable que exista alguna entidad jurídica de la cual los poderes constituidos y el propio Estado carezcan de jurisdicción, es decir, una entidad jurídica superior, anterior y exterior al propio Estado. ${ }^{23}$

No por nada, para el maestro Pereira Menaut, el imperio del derecho ${ }^{24}$ debe poseer las siguientes características:

- Sumisión de todos los poderes -incluidos las constituciones y los tribunales supremos o constitucionales - a los principios generales del derecho natural, a la igualdad, a la dignidad y, en suma, a los derechos humanos.

- Sumisión de todos los poderes públicos a la Constitución.

— Sumisión del Ejecutivo a las leyes y a las sentencias judiciales.

Es por lo anterior que la idea de considerar que pueda existir un poder constituido que se encuentre exento de cualquier tipo de control, es un

23 Cuando hacemos referencia a entidad jurídica que sea "superior, exterior y anterior" al propio Estado, queremos referirnos a fuentes del derecho que no dependan de la potestas normando que poseen los órganos estatales. Por ejemplo, es claro que el derecho internacional de los derechos humanos son claramente una fuente de derechos que se encuentra, hoy más que nunca, en una relación de superioridad respecto de las Constituciones nacionales, sobre todo porque al momento de ratificar algún tratado internacional en la materia, el Estado nacional se obliga a cumplirlo de buena fe y sin que exista la posibilidad de alegar cuestiones de derecho interno que justifiquen su incumplimiento, por lo que, aun cuando el tratado internacional fuere contrario a la Constitución de tal Estado, deberá aplicarse aquél, precisamente por los principios de buena fe y pacta sunt servanda. De igual forma, cuando hablamos de costumbres que pueden llegar a imponerse frente al derecho vigente y escrito, es decir, que se configuran en costumbres derogatorias, sin duda estamos en presencia de una fuente de derecho que es exterior al Estado mismo. Y por último, cuando se habla de los fundamentos de los derechos, como lo son, a dicho de Pereira Maneaut, la vida, la libertad, la igualdad o la dignidad, y se les reconoce como valores fundamentales que se configuran en realidades prejurídicas, estamos frente a una fuente de derecho que es - incluso - anterior al propio Estado.

24 Pereira Menaut, Carlos-Antonio, Lecciones de teoría constitucional, México, Porúa-Universidad Panamericana, 2005, p. 86. 
pensamiento que contradice la esencia del constitucionalismo. Si no se reconoce que todo texto constitucional posee un núcleo intangible, expreso o no, implícitamente se está aceptando que es imposible limitar al poder a través del derecho.

Pese a que lo anterior hoy resulta irrefutable, lo cierto es que la visión del iuspositivismo formalista que se arraigó durante el desarrollo del Estado liberal o legislativo de derecho, tuvo un impacto importante en relación con el poder constituyente constituido, al punto de que hoy se duda si dicho poder debe o no quedar sometido al Rule of Law.

El impacto que tuvo el Estado liberal o legislativo de derecho en la función del poder revisor de la Constitución genera hoy en día la percepción de que tal poder debe quedar superpuesto al imperio del derecho o, si se prefiere, éste debe quedar sometido a aquél. Sin embargo, no podemos olvidar que a principios del siglo XIX el filósofo, escritor y politólogo francés Benjamín Constant, ya afirmaba lo siguiente: "He aquí una verdad importante y un principio eterno que es necesario establecer: ningún poder de la tierra es ilimitado, ni el del pueblo, ni el de los hombres que se dicen sus representantes, ni el de los reyes, sea cual sea el título por el que reinen...". ${ }^{25}$

No por nada, Pedro de Vega advierte, y lo hace con razón, que

...la reforma constitucional tiene que verse sometida al reconocimiento de ciertos límites, que en ningún caso se podrán sobrepasar, pues si eso sucediera estaríamos en presencia no de operaciones de reforma... sino ante otros fenómenos como falseamiento de la Constitución, fraude de la Constitución, o sencillamente actos revolucionarios encubiertos... ${ }^{26}$

No obstante, el Estado liberal o legislativo de derecho experimentó una grave crisis que consistió en que el derecho se equiparó a las normas aprobadas por los órganos del Estado, reduciendo así, el imperio del de-

25 Citado por Vega García, Pedro de, "El poder moderador", Cuestiones Constitucionales. Revista Mexicana de Derecho Constitucional, México, núm. 7, julio-diciembre de 2002, p. 222.

26 Vega García, Pedro de, "La reforma constitucional como defensa de la Constitución y de la democracia", en Valadés, Diego y Carbonell, Miguel (coords.), El Estado constitucional contemporáneo. Culturas y Sistemas Jurídicos Comparados, cit., nota 16, t. II, p. 349. 
recho o Rule of Law a sólo un conjunto de autolimitaciones que el Estado se imponía a sí mismo, al punto de que se llega a afirmar que

el Estado de derecho moderno nace con la forma del Estado legislativo de derecho, en el momento en que esta instancia alcanza realización histórica, precisamente, con la afirmación del principio de legalidad como criterio exclusivo de identificación del derecho válido y antes aún existente, con independencia de su valoración como justo. Gracias a este principio y a las codificaciones que son su actuación, una norma jurídica es válida no por ser justa, sino exclusivamente por haber sido "puesta" por la autoridad dotada de competencia normativa... ${ }^{27}$

Con lo cual queda claro que en esta primera fase no habrá más derecho que el producido por el propio Estado. ${ }^{28}$

De esta forma, si quisiéramos reflejar — de acuerdo con la teoría de los conjuntos- la relación existente entre el Estado liberal o legislativo y el derecho, podríamos representarlo de la siguiente manera:

\section{Esquema 1. Estado liberal o legislativo de derecho}

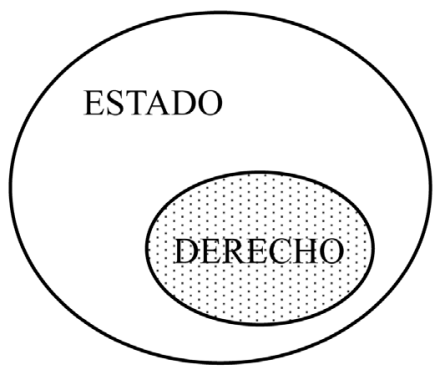

27 Ferrajoli, Luigi, "Pasado y futuro del Estado de derecho", en Carbonell, Miguel (ed.), Neoconstitucionalismo(s), 3a. ed., Madrid, Trotta, 2006, p. 16

28 En palabras de Vigo, tendríamos que referirnos a esta etapa como aquella en la cual “el derecho decimonónicamente hablando se definía por el legislador a través de las leyes y sobre éstas no existía ningún control constitucional. Esta realidad europea cambiará en la segunda mitad del siglo XX mediante la introducción de tribunales que hablaban desde la Constitución, no sólo como legislador negativo, sino hasta modificando y perfeccionando la obra legislativa", véase Vigo, Rodolfo Luis, De la ley al derecho, México, Porrúa, 2003, p. 9. 
El esquema anterior genera una interrogante que nos hace advertir un grave problema: ¿cómo conseguir que el contenido limite al continente?, o en otras palabras, ¿cómo limitar al Estado y al poder por medio del derecho cuando se da por sentado que no hay más derecho que el emanado del mismo aparato estatal?

Por ello es que hemos afirmado que esta primera versión del Estado de derecho se alejó del concepto tradicional de Rule of Law, debido a que el imperio del derecho sólo será posible mientras haya una parte del derecho a la que se le reconozca como entidad jurídica anterior, superior y exterior al propio Estado.

Tal entidad jurídica anterior, superior y exterior al propio Estado sería - de acuerdo con nuestro análisis - el reconocimiento de la existencia del núcleo intangible de la Constitución. Así, la forma en cómo podría representarse lo anterior, acudiendo nuevamente a la teoría de los conjuntos, sería de la siguiente manera:

Esquema 2. Rule of Law o imperio del derecho

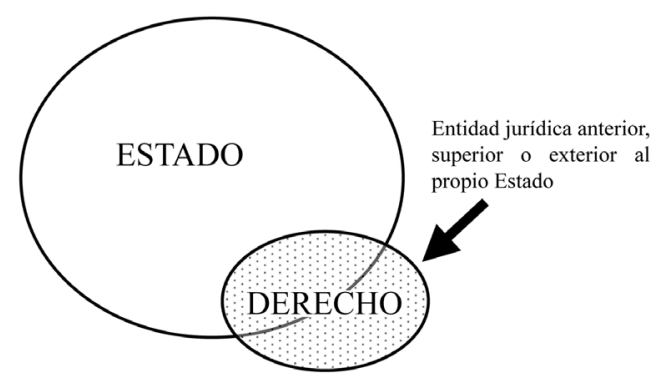

Ahora bien, retomando nuevamente nuestro análisis central, pensemos hipotéticamente que el poder revisor de la Constitución decidiera aprobar una reforma que permitiera la esclavitud en el Estado mexicano. Al aceptar que no existe control alguno en contra de tal reforma, se estaría generando así un ejercicio de poder no limitado por el derecho, o peor aún, la limitación que el derecho debe significar para el poder se convertiría de inmediato en un conjunto de autolimitaciones, ya que implícitamente se estaría aceptando que no hay más derecho que el proveniente del propio poder constituyente permanente, y con ello dicho poder llegaría a 
limitarse —en el mejor de los casos_- sólo cuando así conviniera a sus intereses, o bien, simplemente no se limitaría. ${ }^{29}$

En consecuencia, para hablar de una vivencia efectiva del Rule of Law, o bien, de la existencia de un Estado constitucional y democrático de derecho, debemos decir que es requisito sine qua non la coexistencia de un eficiente sistema de control de constitucionalidad ejercitado por órganos imparciales e idóneos, ya que éste configura la primera garantía para la tutela de los derechos constitucionales, y con ello el primer límite al poder. ${ }^{30}$ De esta forma podemos afirmar categóricamente que, hablar de Estado constitucional sin esquemas de control de la constitucionalidad es un contrasentido.

Sólo será reconociendo la existencia de entidades jurídicas anteriores, superiores o exteriores al propio Estado, así como estableciendo sistemas de control de la constitucionalidad que tutelen dichas entidades, las vías para concretar el Rule of Law, y de esta manera consolidar al Estado constitucional y democrático de derecho.

Por ejemplo, continuando con el análisis del caso hipotético, la única vía para frenar una pretensión del poder de reforma constitucional en ese sentido, sería atendiendo a una entidad jurídica exterior, anterior y/o superior al propio Estado, es decir, una entidad que no dependa del poder revisor de la Constitución, y que incluso sea anterior a él mismo. Nos referimos aquí al valor fundamental de la libertad, el cual, al ser una realidad prejurídica que sirve de fundamento a un sinnúmero de derechos, se configura en una entidad jurídica exterior y anterior al Estado, razón por la cual, el Estado (incluido el poder constituyente permanente), no puede sino reconocer y tutelar.

29 Si a lo anterior agregamos que en México: 1) el poder constituyente permanente se integra de los diputados y senadores del Congreso de la Unión y de los legisladores de los congresos de cada uno de los estados miembros de la Federación; 2) que de acuerdo con uno de los principios derivados de la Revolución mexicana no está permitida la reelección inmediata de legisladores, lo que provoca - simultáneamente- un acercamiento de dichos servidores públicos a los intereses de los partidos políticos que los postulan y un alejamiento a los intereses de sus representados; 3) que en nuestro sistema electoral no se permiten las candidaturas independientes o ciudadanas; 4) que dicho poder revisor de la Constitución no tiene límite alguno — ni formal, ni material—, por lo que de las premisas antes señaladas válidamente tendríamos que concluir que en nuestro país, el derecho y los límites al poder se encuentran en manos de los partidos políticos mayoritarios.

30 Sagüés, Néstor Pedro, El sistema de derechos, magistratura y procesos constitucionales en América Latina, México, Porrúa, 2004, t. I, p. 27. 
Ahora bien, si para algunos el argumento anterior encontrare explicación sólo en el incómodo iusnaturalismo aristotélico-tomista, podríamos quizá referirnos al artículo 8.1 del Pacto Internacional de Derechos Civiles y Políticos, el cual establece que "nadie estará constreñido a esclavitud. La esclavitud y la trata de esclavos estarán prohibidas en todas sus formas...".

Así, apegándonos estrictamente a un contenido jurídico-positivo que no depende de la potestas normando del Estado y, sobre todo, que por provenir del derecho internacional de los derechos humanos se configura en una entidad jurídica exterior y superior al propio Estado, colocándose incluso en una relación de superioridad respecto de cualquier Constitución nacional, se estaría concretando el Rule of Law.

De esta forma, sea cual fuere el argumento utilizado, lo cierto es que el Estado sólo se verá eficazmente limitado si comenzamos por reconocer la existencia de entidades jurídicas que cumplan con las características antes mencionadas.

Es por ello que realizaremos un análisis de la doctrina jurisprudencial.

\section{LA SUPREMA CORTE MEXICANA Y EL NÚCLEO INTAGIBLE DE LA CONSTITUCIÓN}

...la modificación de algunos elementos nucleares de una ley fundamental supondría la aprobación de una nueva Constitución... ${ }^{31}$

José Julio FERNÁNDEZ RODRÍGUEZ

Una vez que hemos vislumbrado los conceptos básicos de la teoría constitucional que resultan aplicables al presente análisis, procederemos a verificar cuál es el estatus que guarda la doctrina jurisprudencial que ha venido desarrollando la Suprema Corte de Justicia de la Nación (SCJN), tratándose de controlar las reformas a la ley fundamental.

31 Fernández Rodríguez, José Julio y Auzmendi del Solar, Montserrat, "Reforma constitucional y Constitución Española de 1978", en Rosario Rodríguez, Marcos del (coord.), Supremacía constitucional, México, Porrúa-Universidad Panamericana, 2009, p. 98 . 


\section{El precedente “Camacho” (amparo en revisión 1334/98)}

En 1999 la SCJN resolvería el famoso caso planteado por Manuel Camacho Solís, cuya resolución sentaría las bases de una doctrina jurisprudencial que afirmaba que el poder constituyente constituido no era un poder ilimitado o exento de control, al señalar en la parte conducente del criterio que

el contenido del dispositivo constitucional [aprobado por el poder reformador de la Constitución] resulta inimpugnable a través de la demanda de garantías, siendo sólo atacable el proceso de reforma correspondiente [toda vez que son] los actos que integran el procedimiento legislativo que culmina con su reforma, lo que se pone en tela de juicio, por lo que pueden ser considerados como autoridades responsables quienes intervienen en dicho proceso, por emanar éste de un órgano constituido, debiendo ajustar su actuar a las formas o esencias consagradas en los ordenamientos correspondientes, conducta que puede ser controvertida mediante el juicio de amparo, por violación al principio de legalidad...32

Cabe señalar que con el criterio anterior, la SCJN aceptaba que las reformas constitucionales deberían ser revisadas al menos formalmente, lo que representaba una cierta apertura del máximo tribunal mexicano a considerar la necesidad de que el poder constituyente permanente estuviera controlado, bajo el argumento de que al ser un órgano constituido, no podía ser considerado un poder ilimitado.

\section{El precedente "San Pedro Quiatoni" (controversia constitucional 82/2001)}

Sin embargo, tres años después de la resolución del caso Camacho, la SCJN al resolver - en septiembre de 2002 - una controversia constitucional interpuesta por el municipio oaxaqueño de San Pedro Quiatoní en contra de la reforma que - en materia indígena - aprobara el poder revisor de la Constitución modificando el artículo 2o. de nuestra carta magna, dio un paso atrás a lo señalado en 1999, enfatizando que

32 Tesis P. LXII/99, Semanario Judicial de la Federación y su Gaceta, Novena Época, t. X, septiembre de 1999, p. 11, registro 193250. 
el procedimiento de reformas y adiciones a la Constitución no es susceptible de control jurisdiccional, ya que lo encuentra en sí mismo; esto es, la función que realizan el Congreso de la Unión, al acordar las modificaciones, las legislaturas estatales al aprobarlas, y aquél o la Comisión Permanente al realizar el cómputo de votos de las legislaturas locales y, en su caso, la declaración de haber sido aprobadas las reformas constitucionales, no lo hacen en su carácter aislado de órganos ordinarios constituidos, sino en el extraordinario de órgano reformador de la Constitución, realizando una función de carácter exclusivamente constitucional, no equiparable a la de ninguno de los órdenes jurídicos parciales, constituyendo de esta manera una función soberana, no sujeta a ningún tipo de control externo, porque en la conformación compleja del órgano y en la atribución constitucional de su función, se encuentra su propia garantía. ${ }^{33}$

\section{El precedente "Comunidad Indigena de Zirahuén, municipio de Salvador Escalante, Michoacán” (amparo en revisión 123/2002)}

Coherente con lo anterior, y configurando una doctrina jurisprudencial consistente en afirmar que el poder constituyente constituido no posee límite alguno, en noviembre de 2002, la Segunda Sala de la SCJN, al resolver un amparo promovido por una comunidad indígena en contra de la reforma ya mencionada al artículo 2o. de nuestra carta magna, señaló nuevamente que

el Constituyente estableció la posibilidad de adicionar o reformar la propia ley fundamental a través de las instituciones representativas de la voluntad de la nación mexicana, sin dar intervención directa al pueblo, esto es, no se prevé medio de defensa alguno para impugnar el contenido de una modificación constitucional, ya que ello atentaría contra el sistema establecido... ${ }^{34}$

Con lo que se confirma que es improcedente el juicio de amparo o cualquier otro tipo de medio de control constitucional en contra del contenido de las reformas constitucionales o de su procedimiento de apro-

33 Tesis P./J. 39/2002, Semanario Judicial de la Federación y su Gaceta, Novena Época, t. XVI, septiembre de 2002, p. 1136, registro 185941.

34 Tesis 2a. CXLI/2002, Semanario Judicial de la Federación y su Gaceta, Novena Época, t. XVI, noviembre de 2002, p. 455, registro 185,509. 
bación, razón por la cual las enmiendas a la ley fundamental quedarán exentas de cualquier tipo de control, sea material o formal.

\section{El precedente "Nueva Alianza y Convergencia" (acción de inconstitucionalidad 168/2007 y su acumulada 169/2007)}

Incluso, y en adición a lo anterior, en abril de 2008, el Pleno de la SCJN admitió a trámite — vía recursos de reclamación — dos acciones de inconstitucionalidad promovidas por dos partidos políticos minoritarios dentro del Congreso de la Unión (Partido Nueva Alianza y Partido Convergencia), que en un principio habían sido desechadas.

Estas dos acciones de inconstitucionalidad versaron precisamente sobre el procedimiento de reformas - que en materia electoral - aprobara el constituyente permanente en noviembre de 2007, abordando tangencialmente el tema central del presente estudio.

En tales procesos constitucionales se llegó a discutir el tema de si es aceptable o no someter a control las reformas constitucionales. Incluso el ministro Genaro D. Góngora Pimentel sugirió, en una de sus intervenciones, que la votación final del asunto versara sobre lo siguiente: "Primero. ¿Es posible controlar las reformas constitucionales? Segundo. ¿Este control abarca violaciones formales y materiales? Tercero. La acción de inconstitucionalidad ¿es la vía adecuada?". ${ }^{35}$

Pese a lo anterior, decimos que en estas acciones de inconstitucionalidad se abordó el tema central del presente estudio de manera tangencial, debido a que lo que se votó - en última instancia - no fueron los temas sugeridos por el ministro Góngora, sino que se decidió sólo respecto de la procedencia, improcedencia o sobreseimiento de tales acciones de inconstitucionalidad.

Así fue como el pleno de la SCJN resolvió - con una mayoría de siete votos contra cuatro- que las acciones de inconstitucionalidad deberían ser sobreseídas, ya que

...de la interpretación integral del artículo 105, fracción II, constitucional, así como de una interpretación teleológica, se advierte que la acción de in-

35 Extracto de la versión taquigráfica de la sesión pública ordinaria del Pleno de la SCJN, celebrada el 26 de junio de 2008 con motivo de la acción de inconstitucionalidad $168 / 2007$ y su acumulada 169/2007, p. 63. 
constitucionalidad es un medio de control de las leyes, en sentido estricto, esto es, de aquellas expedidas por el legislador ordinario federal, estatal, o del Distrito Federal, y de tratados internacionales, mas no de cualquier otro conjunto normativo... por lo que no puede sostenerse que la acción de inconstitucionalidad permita impugnar reformas constitucionales, pues por un lado no se aprueban por el legislador ordinario, tampoco puede considerarse a la Constitución federal como una ley federal, estatal o del Distrito Federal; y por último, es relevante considerar que quienes promueven las presentes acciones, son partidos políticos nacionales los que tienen delimitada su legitimación en cuanto al ámbito de aplicación y ámbito material de las normas generales impugnadas, es decir, sólo pueden impugnar leyes electorales federales, locales, y dependiendo además de su registro, ya sea como partido nacional o local. Por consiguiente, al no ser la acción de inconstitucionalidad el medio para impugnar reformas y adiciones a la Constitución federal, esta Suprema Corte no puede conocer del asunto... ${ }^{36}$

Sin embargo, lo interesante del debate que se suscitó en el Pleno de nuestro máximo tribunal, en aquella sesión del 26 de junio de 2008, es que algunos de los ministros comenzaron a dar razones para abandonar la doctrina jurisprudencial — hasta ese entonces imperante - de que las reformas constitucionales no pueden ser objeto de control constitucional.

Por ejemplo, el ministro Sergio Salvador Aguirre Angiano sostenía

...que sí somos cancerberos para impedir que por el arco de la Constitución, entren remedos de normas constitucionales que se aparten de su validez contenida y preceptuada en el artículo 135 constitucional. Esas falsas normas constitucionales debemos de atajarlas, porque no son Constitución. ${ }^{37}$

Con ello, el ministro Aguirre - aun cuando no compartía la idea de realizar un control material de las enmiendas a la Constitución-, dejaba en claro que es misión de un tribunal constitucional verificar que dichas reformas hayan sido aprobadas conforme al procedimiento establecido en la misma.

Por su parte, el ministro José Ramón Cossío Díaz manifestaba que

...a diferencia de lo que plantea el proyecto, creo yo que existen sólidos argumentos jurídicos para entender en una interpretación sistemática no literal,

36 Ibidem, p. 7.

37 Ibidem, p. 59. 
de la expresión "leyes", que sí estamos en la posibilidad de entrar a conocer de la regularidad de las reformas constitucionales por vía de acción de inconstitucionalidad. ${ }^{38}$

En este punto, el ministro Cossío lo que manifiesta es que el concepto de norma general utilizado por el artículo 105, fracción 2 de nuestra carta magna, debe interpretarse en un sentido amplio, concepto dentro del cual caben perfectamente las reformas a la ley fundamental.

De igual manera, el ministro Genaro D. Góngora Pimentel, haciendo referencia al proyecto de sentencia que presentó en este caso el ministro Sergio Armando Valls Hernández, coincidía

...con las consideraciones en torno al control formal de las reformas constitucionales que nos explica don Sergio Valls, pues como ya lo he sostenido en otras ocasiones, las reformas constitucionales se llevan a cabo mediante un procedimiento complejo, con reglas claras en cuyo desarrollo pueden presentarse vicios, como en cualquier otro; así, para considerar que nuestra República es auténticamente representativa y democrática como lo establece el artículo 40 constitucional, resulta necesario que exista certeza de que las modificaciones a la norma constitucional son realizadas conforme a lo previsto por la propia Constitución y para ello el control jurisdiccional del órgano reformador resulta indispensable... ${ }^{39}$

Al respecto, nos parece que el argumento utilizado por el ministro Góngora resulta muy interesante, ya que nos permite advertir que si se acepta apriorísticamente que el procedimiento de reforma constitucional encuentra en sí mismo su control, esto daría pie a generar un dogma constitucional peligroso.

Tan peligrosa sería esta forma de pensar que el mismo ministro Góngora continuaba diciendo que resultaba adecuada

...la propuesta del proyecto, de apartarnos del criterio de que la reforma constitucional encuentra su control en sí misma... Afirmar que la verificación de esta regla es en sí misma el control, torna al Congreso - como lo ha dicho en algunas ocasiones don Sergio Valls - o a su Comisión Permanente, en un órgano autorreferente, ¿qué pasaría si con la aprobación de un número de legislaturas insuficiente esta Comisión Permanente declarara hecho el 
cómputo, ella misma es la que se va a controlar y revocar su declaración?... La composición compleja del órgano [léase poder constituyente constituido] es un requisito básico para reformar la Constitución, pero esta situación no le dota de un halo de infalibilidad. ${ }^{40}$

Más aún, lo que resulta ciertamente interesante para el análisis que nos hemos planteado como objetivo del presente estudio, son las consideraciones que el propio Góngora realizara en torno a la posibilidad de efectuar un control material de las reformas constitucionales, al decir que

...también el contenido material de las reformas a la Constitución puede ser materia de control por parte de este alto tribunal; el proyecto se basa en el argumento de que nuestra Constitución no prevé límites expresos o cláusulas de intangibilidad que otorguen una protección especial a ciertas materias frente a la actuación del órgano reformador; sin embargo, la Constitución no se reforma a sí misma, lo hace el Congreso de la Unión y las legislaturas locales como órganos constituidos que están sometidos; me parece que hay límites que la Constitución no establece expresamente, pero que se deducen claramente como exigencias de la propia Constitución, que imponen límites inmanentes o implícitos a la actuación del órgano reformador. ${ }^{41}$

A nuestro parecer, el punto de vista sostenido por el ministro Góngora encuentra su justificación en conceptos propios de la teoría constitucional, los cuales permiten concebir a la Constitución no sólo como un documento jurídico, sino entender que posee una esencia binaria, configurándose no sólo en texto jurídico, sino también en un documento político. Esta doble esencia, que dicho sea de paso, es una de las diferencias fundamentales entre Constitución y ley, permite afirmar que en la primera existen contenidos que reflejan aquellas decisiones políticas fundamentales de las que hablaba Schmitt, o bien, decisiones axiológicas fundamentales que el pueblo pretende concretar en determinado tiempo y lugar. De ahí que en la interpretación constitucional no sólo deba atenderse a elementos explícitos de su texto, sino también a elementos implícitos.

Asimismo, señala el citado ministro que no puede escapar al análisis de la SCJN las limitantes internacionales que en forma de obligaciones ha venido asumiendo el Estado mexicano al ratificar diversos tratados in-

40 Ibidem, p. 10.

41 Ibidem, p. 11. 
ternacionales, entre ellos la Convención Americana sobre Derechos Humanos, según la cual - por ejemplo- se dispone que aquellos Estados que han eliminado la pena de muerte, no pueden en ningún momento y bajo ninguna circunstancia volver a establecerla, configurándose así un límite explícito para el poder revisor de la Constitución.

Por ello, señala Góngora que: "a pesar de que la Constitución no lo diga... se deducen con claridad límites materiales a las reformas constitucionales". ${ }^{42}$

El argumento anterior nos permite reflexionar sobre un tema poco analizado en el campo de la interpretación constitucional. Nos referimos a los silencios constitucionales, es decir, a aquellas omisiones en las que incurre el poder constituyente - quizá premeditadamente-y que nos obligan a preguntarnos cuando estamos frente a ellas, si lo correcto será deducir potestades ilimitadas para los órganos constituidos, o si bien, deben ser — tales silencios constitucionales - interpretados a la luz del constitucionalismo y sus fines.

En gran medida, el debate mexicano en torno a los límites del poder constituyente constituido se concentra en responder esta interrogante. Así, frente a los silencios constitucionales que en este tema en concreto posee la Constitución mexicana, es decir, la falta de límites expresos o cláusulas de intangibilidad que otorguen una protección especial a ciertos contenidos frente a la actuación del órgano reformador, puede concluirse que tales silencios otorgan un poder ilimitado al órgano de reforma constitucional, y que por lo tanto puede modificar del texto constitucional lo que le venga en gana. Sin embargo, consideramos que tal conclusión no es del todo acertada.

No por nada, el Tribunal Constitucional peruano ya ha mencionado que

...los silencios constitucionales no pueden ser interpretados como tácitas concesiones al legislador, a efectos de que expida regulaciones desvinculadas de la norma fundamental. Allí donde las "normas regla" previstas en la Constitución omiten precisiones ( $v \cdot g r$. procedimiento de reforma constitucional), la ley o, en su caso, el reglamento parlamentario están obligados a estipularlas, pero siempre en vinculación directa a las "normas principio" 
(v. $g r$. los principios del constitucionalismo) contenidas en la propia norma fundamental. ${ }^{43}$

En una misma línea argumentativa, la Corte Constitucional italiana ha llegado a admitir que los límites del poder revisor existen a pesar de que el poder constituyente no los establezca. Así, en la sentencia 1146/1988 señaló que

la Constitución italiana contiene algunos principios supremos que no pueden ser subvertidos o modificados en su contenido esencial ni siquiera por leyes de reforma constitucional o por otras leyes constitucionales. Tales son los principios que la misma Constitución explícitamente prevé como límites absolutos al poder de reforma constitucional, como la forma republicana, como los principios que, a pesar de no estar mencionados expresamente... pertenecen a la esencia de los valores supremos sobre los que se funda la Constitución italiana. [Así las cosas,] los principios supremos del ordenamiento tienen una valencia superior respecto a las otras normas o leyes de rango constitucional... por tanto, negar que esta Corte es competente para juzgar la conformidad de las leyes de reforma constitucional y de las otras leyes constitucionales... en relación a los principios supremos, [nos llevaría] al absurdo de considerar el sistema de garantías jurisdiccionales de la Constitución como defectuoso o no efectivo en relación a sus normas de más elevado valor. ${ }^{44}$

De igual manera, el Tribunal Constitucional de Perú manifestó en los fundamentos 33 y 34 de la sentencia del expediente 0050-2004-AI/TC, que

los límites explícitos no se agotan en las cláusulas de intangibilidad, sino que a lo largo del texto constitucional pueden estar consignados incluso en frases que se encuentran en un contexto diferente. [Son los denominados] límites materiales implícitos, [que] son aquellos principios supremos de la Constitución contenidos en la fórmula política del Estado y que no pueden ser modificados, aun cuando la Constitución no diga nada sobre la posibilidad o no de su reforma, ya que una modificación que los alcance sencillamente implicaría la "destrucción" de la Constitución. Tales son los casos de los principios re-

43 Cfr. Sentencia del Tribunal Constitucional Peruano, expediente 0006-2003-AI/TC, 1o. de diciembre de 2003.

44 Sentencia 1146/1988, Giudizio di legittimità costituzionale in via incidentale, 15 de diciembre de 1988, http://www.cortecostituzionale.it/ 
feridos a la dignidad del hombre, soberanía del pueblo, Estado democrático de derecho, forma republicana de gobierno y, en general, régimen político y forma de Estado. 45

Por lo anterior, sería absurdo pensar que ante este tipo de silencios constitucionales deban deducirse potestades ilimitadas para los órganos constituidos (como lo es el poder constituyente constituido) que, incluso, puedan convertirse en potestades contrarias al constitucionalismo mismo.

Los argumentos anteriores, así como su contenido, reflejan la forma de proceder de lo que en otros trabajos he denominado intérpretes artífices, que son aquellos aplicadores jurídicos que al considerar a la Constitución como un documento vivo y dinámico, buscan respuestas nuevas que no necesariamente están explícitas en el texto de la ley fundamental, pero que sin duda posibilitan la aplicación coherente de la misma. ${ }^{46}$

\section{El amparo "Centro Empresarial de Jalisco, Sindicato Patronal" (amparo en revisión 186/2008)}

Como ya hemos mencionado, en la resolución del anterior precedente, se comenzaba a vislumbrar - al menos en la minoría disidente - una evolución de la doctrina jurisprudencial que hasta ese entonces señalaba que el poder revisor de la Constitución no poseía límite alguno, o más bien, que el límite lo encontraba en sí mismo.

Así, a un año de distancia de la resolución de la acción de inconstitucionalidad 168/2007 y su acumulada 169/2007, es decir, el 29 de septiembre de 2008, en uno de los múltiples amparos promovidos por las organizaciones patronales en contra de la debatida reforma constitucional en materia electoral de 2007 (amparo en revisión 186/2008), y sobre el cual había recaído un acuerdo desechando el amparo por notoria improcedencia, la SCJN en ejercicio de la facultad de atracción que le confiere nuestra Constitución, resolvía que tales proveídos no eran jurídicamente

45 Cfr. Sentencia del Tribunal Constitucional Peruano, expediente 0050-2004-AI/TC, 5 de junio de 2005, párrs. 33 y 34.

46 Cfr. Vázquez-Gómez Bisogno, Francisco, "Intérpretes arqueólogos vs. intérpretes artífices. El caso Lydia Cacho”, en Báez Silva, Carlos et al. (coords.), Interpretación, argumentación y trabajo judicial, cit., nota 15, p. 205. 
aceptables, debido a que el hecho de que un amparo fuera promovido en contra de reformas constitucionales no implicaba una notoria improcedencia. ${ }^{47}$

Al respecto, consideramos oportuno rescatar algunas de las consideraciones vertidas por el ministro José Ramón Cossío Díaz (ministro ponente en el caso de referencia) según las cuales, seis de los diez ministros presentes votaron a favor de su proyecto. ${ }^{48}$

El ministro Cossío señaló en una de sus primeras intervenciones las siguientes ideas:

1. ... en el proyecto, se hizo un análisis acerca de si el órgano constituyente permanente... tenía las calidades suficientes para ser un órgano o una autoridad responsable en el juicio de amparo, por eso esa parte del análisis de las características del órgano previsto en el artículo 135 constitucional es extensa, puesto que en algunos precedentes, tanto de amparo como en controversia constitucional y de acción, algunos de los señores ministros han hecho consideraciones en cuanto a lo que podríamos denominar la naturaleza jurídica de ese órgano.

2. Sin embargo, y con independencia de esto, me parece que el único tema a resolver en el momento procesal que nos ocupa es si el desechamiento de plano determinado por el juez de distrito, primero, del estado de Jalisco, y por los otros jueces de distrito, de la larga lista de asuntos que tenemos en la misma materia, es manifiesto e indudable, o no lo es...

3. ... me parece que la cuestión ni siquiera es un tema de procedencia, en términos de los artículos 73 y 74 de la Ley de Amparo, sino exclusivamente si este tipo de demandas están o no están comprendidas en el artículo 145 de la Ley de Amparo.

4. Por esas razones, señor presidente, yo considero que existiendo distintos precedentes de esta Suprema Corte en la materia, los cuales podremos referirnos sin duda en el transcurso de la discusión del asunto, no se surte esta causal de desechamiento por un motivo manifiesto e indudable [sino que] se debe admitir el juicio y el juez de distrito estará en su libertad de analizar las condiciones de la procedencia o improcedencia con fundamento en otras cau-

47 Los jueces de distrito han desechado estas demandas con fundamento en el artículo 145 de la Ley de Amparo, el cual establece: "El juez de distrito examinará ante todo, el escrito de demanda; y si encontrare motivo manifiesto e indudable de improcedencia, la desechará de plano, sin suspender el acto reclamado".

48 Cabe señalar que en esta sesión no estuvo presente el ministro en retiro Mariano Azuela Güitrón. 
sales o en su caso, dictar una sentencia de fondo, analizar las condiciones de los efectos, en fin, todos ellos temas complejos, pero no desecharlo de plano como lo hizo en el caso concreto que nos ocupa... ${ }^{49}$

En suma, e independientemente del tema de fondo que implicaba la revisión del amparo comentado, lo que el ministro Cossío refería es que no se actualizaba el supuesto determinado por el artículo 145 de la Ley de Amparo, debido al cúmulo de precedentes que al respecto ha establecido la SCJN, por lo que debía reponerse el proceso a efecto de que el juez de distrito correspondiente pudiera entrar al estudio del asunto. Como ya lo hemos señalado, esta fue la decisión de la mayoría.

Ahora bien, consideramos fundamental para cumplir a cabalidad el objetivo que nos hemos trazado al desarrollar el presente apartado, rescatar algunos de los planteamientos realizados por los otros ministros en torno a nuestra cuestión: ¿es el poder revisor de la Constitución un poder que puede ser sujeto a control jurisdiccional?

Al respecto, el ministro Góngora siendo coherente con la postura que venía sosteniendo señalaría que:

toda Constitución contiene un núcleo que define su identidad así como la continuidad del Estado, por lo que necesariamente es inmodificable, esta inmodificabilidad se configura como un componente básico de la defensa de la Constitución y constituye el fundamento de la imposibilidad de suprimir el orden constitucional en su totalidad, o en las partes nucleares, y sustituirlo por otro distinto, mediante un procedimiento de reforma. ${ }^{50}$

Después, el ministro Góngora no repararía en señalar cuáles eran esas partes nucleares a las que debe quedar sometido y limitado el poder constituyente constituido, siendo éstas las siguientes:

...las cuestiones que establecen en torno a la soberanía popular, los derechos fundamentales, en cuanto se configuran como las normas de reconocimiento del ordenamiento jurídico, cuya premisa es la dignidad humana, la cláusula

49 Todas estas consideraciones son extractos de la versión taquigráfica de la sesión pública ordinaria del Pleno de la SCJN, celebrada el 29 de septiembre de 2008, con motivo del amparo en revisión 186/2008, pp. 4-6.

50 Ibidem, p. 9. 
democrática, en cuanto legitima el orden constitucional, la división de poderes, en cuanto implica una limitación del poder... ${ }^{51}$

Conceptos - los anteriores - que se configuran en fundamentales dentro de la teoría constitucional, al punto de que sólo habría que recordar lo que los revolucionarios franceses señalaron en el artículo 16 de la Declaración de los Derechos del Hombre y del Ciudadano de 1789: "Toda sociedad en la cual no esté establecida la garantía de los derechos, ni determinada la separación de los poderes, carece de Constitución”.

\section{El amparo "Asociación de Industriales y Empresarios de Morelos".}

Un primer límite al poder constituyente constituido (amparo 1753/2007)

Como ya lo mencionábamos, en la resolución emitida por la SCJN en el amparo en revisión 186/2008 se concluyó que las demandas de amparo promovidas en contra de la cuestionada reforma constitucional de noviembre de 2007, no actualizaban el supuesto determinado por el artículo 145 de la Ley de Amparo, debido a que no existía en ellas un motivo manifiesto e indudable de improcedencia.

Esta resolución generó todo tipo de reacciones en el foro jurídico, pero sobre todo en el ámbito del Poder Judicial federal, toda vez que la resolución de la SCJN contiene un mensaje muy claro para los integrantes de dicho Poder:

se debe admitir el juicio y el juez de distrito estará en su libertad de analizar las condiciones de la procedencia o improcedencia con fundamento en otras causales o, en su caso, dictar una sentencia de fondo, analizar las condiciones de los efectos, en fin, todos ellos temas complejos, pero no desecharlo de plano... 52

Pues en uso de esa autonomía jurisdiccional reconocida por la SCJN a los juzgadores de amparo, fue que Florida López Hernández, jueza séptima de distrito del Centro Auxiliar de la Segunda Región, con sede en San Andrés Cholula, Puebla, con fecha 8 de mayo de 2009, resolvió el

51 Ibidem, p. 10.

52 Ibidem, p. 6. 
recurso de amparo 1753/2007 promovido por el representante legal de la "Asociación de Industriales y Empresarios de Morelos", Sindicato Patronal (ADIEM-Coparmex), en contra del decreto que reforma los artículos 6o., 41, 85, 99, 108, 116 y 122, adiciona el artículo 134 y deroga un párrafo del artículo 97 de la Constitución Política de los Estados Unidos Mexicanos, publicado en el Diario Oficial de la Federación del 13 de noviembre de 2007.

Sin temor a equivocarnos, debemos afirmar que esta resolución será un referente en la historia de la justicia constitucional mexicana, pues se trata de la primera sentencia en la que se otorgó el amparo y protección de justicia federal en contra de una enmienda a la carta magna, es decir, en contra de un acto del poder reformador de la Constitución.

En el segundo de los puntos resolutivos de la sentencia de mérito se puede leer lo siguiente:

SEgUnDO. La justicia de la Unión ampara y protege a "ASOCIACIÓN DE INDUSTRIALES Y EMPRESARIOS DE MORELOS”, SINDICATO PATRONAL, ADIEMCOPARMEX a través de Manuel Juan Rodríguez Lomelí en su carácter de presidente, contra del Congreso de la Unión, del presidente de la República, del secretario de Gobernación y del director del Diario Oficial de la Federación, respecto del decreto de reforma del artículo 41 apartado "A" penúltimo párrafo, constitucional, publicado en el Diario Oficial de la Federación el trece de noviembre de dos mil siete, en términos y para los efectos precisados en el último considerando de este fallo.

Ahora bien, es importante mencionar que la inconstitucionalidad del mencionado precepto de nuestra ley fundamental fue derivada de un control de tipo formal, es decir, que aun cuando en el análisis de la jueza López Hernández, se abordaron muchos de los argumentos mencionados en el precedente analizado en el apartado anterior, lo cierto es que centró su estudio en el proceso legislativo que siguió la reforma constitucional impugnada, concluyendo que

al no llevarse conforme a lo previsto en el artículo 135 constitucional, el proceso legislativo de la reforma publicada en el Diario Oficial de la Federación el trece de noviembre de dos mil siete, del artículo 41 apartado "A", penúltimo párrafo constitucional, procede el amparo y la protección de la justicia federal para el efecto de que al quejoso no se le aplique en el presente y para 
el futuro el artículo reclamado todo ello para restituirlo en la garantía individual violada, conforme al artículo 180 de la Ley de Amparo. ${ }^{53}$

La razón fundamental que esgrimió la jueza de distrito para deducir un vicio en el proceso legislativo de la reforma constitucional fue que

no obra en la publicación del Diario Oficial de la Federación publicado el trece de noviembre de dos mil siete, en términos de lo previsto en el artículo 135 constitucional, el nombre de las legislaturas de los estados que aprobaron tales reformas [por lo que] al no cumplir los actos reclamados con esos requisitos de fondo y esencia, vulneran las garantías individuales de audiencia, de seguridad jurídica y de legalidad que los artículos 14 y 16 de la ley suprema otorgan a los destinatarios de esos mismos actos reclamados... desde el momento mismo en el que los actos dejan en completo estado de indefensión y en la incertidumbre jurídica para conocer si efectivamente esas enmiendas constitucionales deben acatarse por formar parte de la propia ley suprema, o si por el contrario, carecen de validez legal al no haberse hecho el cómputo y la declaratoria de la aprobación mayoritaria por parte de las legislaturas de los estados de la República. A lo que debe agregarse la violación de la garantía de legalidad, en virtud de que en los actos reclamados no consta que se hayan cumplido los mencionados requisitos previstos en el segundo párrafo del artículo 135 constitucional. ${ }^{54}$

Del análisis de este precedente podemos arribar a las siguientes conclusiones:

1. Que aun cuando no se haya realizado un control material de las reformas constitucionales, con el solo ejercicio del control formal, parecería que la doctrina jurisprudencial a la que nos hemos referido en este capítulo se acerca a la necesidad de limitar al poder reformador, al menos desde el punto de vista formal.

53 Amparo 1753/2007 promovido por el representante legal de la "Asociación de Industriales y Empresarios de Morelos”, Sindicato Patronal (ADIEM-COPARMEX), Florida López Hernández, jueza séptima de distrito del Centro Auxiliar de la Segunda Región, con sede en San Andrés Cholula, Puebla, 8 de mayo de 2009, p. 101.

54 Ibidem, pp. 74, 97 y 98. 
2. Desde ahora queremos advertir que este tipo de resoluciones, aunque pudieran considerarse de vanguardia, ${ }^{55}$ lo cierto es que generan problemas constitucionales de gran magnitud. Esto es así debido al principio de relatividad de las sentencias que priva en el juicio de amparo mexicano, según el cual, la sentencia emitida sólo beneficia al sujeto que acuda a solicitar la protección de la justicia constitucional, por lo que en este caso, es sólo a la persona moral quejosa

55 En este punto debemos aclarar que al hablar de una "resolución de vanguardia" hemos querido significar simplemente que es una primera sentencia que puede servir como arranque para la construcción de una doctrina jurisprudencial en torno a la limitación del poder reformador de la Constitución. Lo puntualizamos así, ya que "vanguardia" también suele ser definida como el punto más avanzado o adelantado a los demás, y consideramos que esta resolución tiene dos crasos errores técnico-jurídicos, razón de más para concluir que no es una sentencia adelantada a su época. Los defectos e inconsistencias radican en lo siguiente: (i) No consideramos que derivado del texto de artículo 135 constitucional ("El Congreso de la Unión o la Comisión Permanente en su caso, harán el cómputo de los votos de las legislaturas y la declaración de haber sido aprobadas las adiciones o reformas"), deba concluirse que en tal declaratoria deben señalarse las legislaturas de los estados que votaron a favor y aquellas que votaron en contra. Si la conclusión antes referida fuera la correcta, si la formalidad del proceso legislativo tuviera tales alcances, deberíamos también invalidar las reformas constitucionales que no incluyan el nombre de los diputados y senadores del Congreso de la Unión que estuvieron presentes en las votaciones correspondientes, así como el sentido de su voto, a fin de que los ciudadanos pudiéramos determinar si tales enmiendas fueron aprobadas por la mayoría calificada que establece nuestra Constitución. Por tal razón, nos parece que es extremo el interpretar el proceso legislativo de esa manera. Ahora bien, con ello no queremos decir que no deban cuidarse tales formalidades, por el contrario, deben cuidarse, razón por la cual los expedientes parlamentarios deben ser lo suficientemente públicos e integrales, pero de ahí a pensar en que deba publicarse en el Diario Oficial de la Federación todo su contenido, nos parece un poco alejado de la realidad y de la propia norma constitucional; (ii) Asimismo, la jueza incurre en un error evidente, ya que al sostener su resolución en el argumento de que se ha violentado el procedimiento de reforma constitucional, declarando sólo la inconstitucionalidad de un párrafo de la reforma constitucional analizada, nos lleva a preguntarnos lo siguiente: si el vicio se presentó en el procedimiento legislativo, $¿$ dicha irregularidad no debe afectar a todas las normas producidas por tal procedimiento?, es decir, como bien lo cuestiona Pedro Salazar, "¿acaso la supuesta irregularidad formal no valía igualmente para todas y cada una de las disposiciones modificadas?", sin duda; es por ello que nos parece una resolución bastante criticable. Véase Salazar Ugarte, Pedro, "Una Corte, una jueza y un réquiem para la reforma constitucional electoral", en Córdova Vianello, Lorenzo y Salazar Ugarte, Pedro (coords.), Democracia sin garantes. Las autoridades vs. la Reforma electoral, México, UNAM-Instituto de Investigaciones Jurídicas, 2009, p. 51. 
a la que no le será aplicable esa porción normativa de la Constitución, lo que podría llegar a generar - multiplicando el número de quejosos y de amparos concedidos en condiciones similarestantas Constituciones como mexicanos hayan solicitado y obtenido amparos en contra de enmiendas a la ley fundamental, es decir, habría tantas Constituciones como personas amparadas.

Aunado a lo anterior, el hecho de que la Constitución no sea la misma para todos — dirían algunos - rompe con el principio de supremacía constitucional, ya que "el atributo de ser superior es imponible a particulares y órganos de autoridad [estando] todos sujetos a lo que diga su texto... nadie queda al margen de su función normativa". ${ }^{56}$ No cabe duda que lo anterior - dicho sea de paso - redundaría en la generación de una inseguridad jurídica de insospechadas proporciones.

Por ello, consideramos oportuno realizar una primera advertencia en el sentido de que el control de reformas constitucionales no debe ser $a$ posteriori, es decir, no puede realizarse una vez que la reforma ya ha entrado en vigor. De tal advertencia quizá debamos arribar a una conclusión prima facie, en el sentido de que cualquier medio de control que se establezca sobre las enmiendas constitucionales debe ser a priori, a efecto de no generar problemas como los descritos.

3. Que con resoluciones de este tipo se deja ver que el objeto de análisis del presente estudio no sólo es actual, sino que además requiere una reflexión lo suficientemente profunda como para lograr arribar a conclusiones correctas.

Esa actualidad y necesaria reflexión a las que nos hemos referido, invitan a manifestar contundentemente que, en relación con el tema, no todo está dicho, y más aún, no todo está definido, por lo que con precedentes como el analizado en el presente inciso, así como el que se analizará a continuación, la conclusión a la que - aparentemente - nos hemos acercado es a la de afirmar que no existe, en torno al control constitucional de las enmiendas a la carta magna, una doctrina jurisprudencial homogénea y coherente de la SCJN o del Poder Judicial de la Federación. Conclusión

56 Arteaga Nava, Elisur, Derecho constitucional, 3a. ed., México, Oxford, 2008, p. 3. 
que, dicho sea de paso, justifica de manera muy importante la elaboración de esta investigación.

\section{El amparo "Consejo Coordinador Empresarial, A. C.".} Una muestra de la cambiante doctrina jurisprudencial (amparo 1566/2007-VI)

Tal es la incertidumbre a la que nos hemos referido, que días después de que la jueza López Hernández resolviera el amparo 1753/2007, es decir, el 20 de mayo de 2009, David Cortés Martínez, juez decimocuarto de distrito en materia administrativa en el Distrito Federal, determinó sobreseer el amparo promovido por el Consejo Coordinador Empresarial, A. C. (amparo 1566/2007-VI), y con ello no otorgar el amparo correspondiente, aun cuando existiera la misma ratio petitio (razón de pedir) que la esgrimida por la Asociación de Industriales y Empresarios de Morelos en el amparo 1753/2007.

En dicha resolución, el juez Cortés Martínez manifestó que

es infundado el argumento de la quejosa consistente en que se viola el artículo 135 de la Constitución Política de los Estados Unidos Mexicanos, pues si bien de la lectura del decreto reclamado, publicado el trece de noviembre de dos mil siete, no se advierte el cómputo de los votos mayoritarios de las legislaturas de los estados de la República, ni consta la declaración por el voto mayoritario de dichas legislaturas, también lo es que el precepto constitucional de referencia no establece tal situación; es decir, que se tenga que publicar necesariamente el cómputo de los votos mayoritarios de las legislaturas de los estados de la República y la declaración respectiva. ${ }^{57}$

Asimismo, prosigue el juez Cortés Martínez:

el argumento de que se trata resulta infundado, toda vez que no debe perderse de vista que en el juicio de amparo en materia administrativa, rige el principio de estricto derecho y que la parte quejosa no precisa precepto legal alguno que establezca la obligación de las autoridades que intervienen en el proceso de reforma a la Constitución federal, de publicar el cómputo y

57 Amparo 1566/2007-VI promovido por el representante legal del Consejo Coordinador Empresarial, A. C., David Cortés Martínez, juez decimocuarto de distrito en materia administrativa en el Distrito Federal, 20 de mayo de 2009. 
la declaratoria de que se habla, [por lo que] en ese orden de ideas, tampoco se transgreden las garantías individuales de audiencia, de seguridad jurídica y de legalidad consagradas en los artículos 14 y 16 de la Constitución federal, por no realizarse tales publicaciones, ya que al Poder Legislativo no le es aplicable la garantía de previa audiencia contemplada por el artículo 14 constitucional, en la forma y términos que se respeta tratándose de otro tipo de actos de autoridades, ya que dicha garantía se respeta, en casos como éste, cuando al consignar en sus leyes los procedimientos necesarios para que se oiga a los interesados y se les dé oportunidad de defensa en aquellos casos en que resulten afectados sus derechos... ${ }^{58}$

De esta forma, concluye categóricamente señalando que

...el no publicarse el cómputo de los votos mayoritarios de las legislaturas de los estados de la República y la declaración respectiva, en el decreto por el que se que reforma los artículos 6o., 41, 85, 99, 108, 116 y 122; adiciona el artículo 134 y deroga un párrafo al artículo 97 de la Constitución Política de los Estados Unidos Mexicanos, en el Diario Oficial de la Federación el trece de noviembre de dos mil siete, no transgrede las garantías de legalidad y seguridad jurídica... En consecuencia, ante lo infundado de los conceptos de violación expuestos, lo procedente es negar el amparo solicitado... ${ }^{59}$

Por paradigmático que parezca, con sólo 12 días de diferencia, dos jueces de distrito resolvieron dos casos idénticos de manera completamente diferente, lo que nos deja ver la divergencia de criterios y la disímbola interpretación constitucional que existe al respecto, haciéndose así evidente la complejidad de nuestro objeto de estudio.

No obstante, a pesar del reconocimiento a tal complejidad, lo cierto es que no debemos olvidar aquel principio general del derecho, aquella máxima jurídica que reza: “...ubi eadem est ratio, eadem debet esse juris dispositio... ". ${ }^{60}$ Es por ello que debemos adentrarnos a las profundidades de la teoría constitucional contemporánea para determinar si debe limitarse — - y en qué medida - al poder revisor de la Constitución, porque lo

58 Idem.

59 Idem.

60 Lo que significa: “....donde existe la misma razón, debe tener lugar la misma disposición...”. Véase Soberanes Fernández, José Luis, "Los valores jurídicos en la historia”, en García Ramírez, Sergio (coord.), Los valores en el derecho mexicano. Una aproximación, UNAM-FCE, 1997, p. 448, http://www.bibliojuridica.org/libros/3/1374/24.pdf 
único cierto es que ante casos idénticos no deben emitirse resoluciones tan aparatosamente divergentes.

\section{El recurso de queja del Instituto Federal Electoral.}

Un repentino cambio de criterio

(recurso de queja 11/2008)

Como última muestra de la complejidad que representa el objeto de estudio del presente trabajo, así como de la incertidumbre que priva en la SCJN en torno a los criterios que los ministros han vertido respecto de la posibilidad de controlar jurisdiccionalmente los actos del poder reformador, analizaremos el recurso de queja 11/2008, interpuesto por el Secretario Ejecutivo del Instituto Federal Electoral en contra del proveído de 2 de julio de 2008, dictado por el juez sexto de distrito en el estado de Guerrero, por el que admitió la demanda de amparo promovida por Televimex, S. A. de C. V., registrando dicho juicio con el número 926/2008.

Tal y como ya lo hemos mencionado, derivado de la resolución emitida por la SCJN en el amparo en revisión 186/2008, se concluyó que las demandas de amparo promovidas en contra de la cuestionada reforma constitucional de noviembre de 2007, no actualizaban el supuesto determinado por el artículo 145 de la Ley de Amparo, debido a que no existe en ellas un motivo manifiesto e indudable de improcedencia. De hecho, ya hemos referido que nuestro máximo tribunal señaló que

...se debe admitir el juicio y el juez de distrito estará en su libertad de analizar las condiciones de la procedencia o improcedencia con fundamento en otras causales o en su caso, dictar una sentencia de fondo, analizar las condiciones de los efectos, en fin, todos ellos temas complejos, pero no desecharlo de plano... ${ }^{61}$

Pues de la misma forma en como se admitieron a trámite las demandas en los dos juicios de amparo que fueron analizados en los dos incisos anteriores, el juez sexto de distrito en el estado de Guerrero hizo lo propio con la demanda que interpusiera la empresa Televimex, S. A. de C. V.

61 Extracto de la versión taquigráfica de la sesión pública ordinaria del pleno de la SCJN, celebrada el 29 de septiembre de 2008, con motivo del amparo en revisión $186 / 2008$, p. 6. 
Sin embargo, en este caso y algunos más (recursos de queja 12/2008 y 16/2008), el Instituto Federal Electoral se inconformó ${ }^{2}$ ante la admisión de las demandas, ya que a su dicho, éstas debían ser desechadas por ser notoriamente improcedentes, lo que originó que con fecha 2 de junio de 2009, el Pleno de la Corte analizara si tales autos admisorios debían confirmarse o, en su defecto, debían anularse.

Así las cosas, no fue caprichoso el título del presente apartado (un repentino cambio de criterio), sino que por el contrario encuentra justificación en lo que a continuación expondremos.

Páginas arriba señalamos algunas de las ideas vertidas por el ministro Góngora en las sesiones plenarias que tuvieran lugar el 26 de junio y 29 de septiembre de 2008, so pretexto del análisis de la acción de inconstitucionalidad 168/2007 (y su acumulada 169/2007) y del amparo en revisión 186/2008 respectivamente. En aquellas acaloradas discusiones, el ministro Góngora vertió ideas muy significativas para el objeto de este trabajo, entre las cuales deseamos rescatar las siguientes:

1. El ministro Góngora señalaba el 26 de junio de 2008 lo siguiente:

...coincido con las consideraciones en torno al control formal de las reformas constitucionales... así, para considerar que nuestra República es auténticamente representativa y democrática como lo establece el artículo 40 constitucional, resulta necesario que exista certeza de que las modificaciones a la norma constitucional son realizadas conforme a lo previsto por la propia Constitución y para ello el control jurisdiccional del órgano reformador resulta indispensable... ${ }^{63}$

...también el contenido material de las reformas a la Constitución puede ser materia de control por parte de este alto tribunal... me parece que hay límites que la Constitución no establece expresamente, pero que se deducen claramente como exigencias de la propia Constitución, que imponen límites inmanentes o implícitos a la actuación del órgano reformador. ${ }^{64}$

62 Recordemos que de acuerdo con el artículo 95 de la Ley de Amparo, el recurso de queja es procedente — precisamente - contra los autos dictados por los jueces de distrito o por el superior del tribunal a quien se impute la violación reclamada, en que admitan demandas notoriamente improcedentes.

63 Extracto de la versión taquigráfica de la sesión pública ordinaria del Pleno de la SCJN, celebrada el 26 de junio de 2008 con motivo de la acción de inconstitucionalidad 168/2007 y su acumulada 169/2007, p. 9.

64 Ibidem, p. 11. 
.... pesar de que la Constitución no lo diga... se deducen con claridad límites materiales a las reformas constitucionales. ${ }^{65}$

2. El ministro Góngora señalaba el 29 de septiembre de 2008 que:

...toda Constitución contiene un núcleo que define su identidad así como la continuidad del Estado, por lo que necesariamente es inmodificable, esta inmodificabilidad se configura como un componente básico de la defensa de la Constitución y constituye el fundamento de la imposibilidad de suprimir el orden constitucional en su totalidad, o en las partes nucleares, y sustituirlo por otro distinto, mediante un procedimiento de reforma. ${ }^{66}$

Pues a menos de un año de distancia (2 de junio de 2009), durante el debate realizado so pretexto del análisis y resolución del recurso de queja al que hace referencia el presente inciso, se escuchó una voz que debemos calificar de absoluta coherencia jurisdiccional. Es el caso de la ministra Margarita Luna Ramos, quien manifestó que

...en este recurso de queja no se está haciendo valer ninguna impugnación en relación con las reformas constitucionales; sin embargo, del proyecto, en los únicos dos conceptos de agravio que se hacen valer se están desestimando para determinar que no es una causa notoria y evidente, y que finalmente debiera en un momento dado, de no existir inconveniente, admitir la demanda respectiva. En lo personal, aun cuando está listado el asunto bajo mi ponencia con el criterio ya fijado por la mayoría en los asuntos precedentes, lo cierto es que yo he votado en contra, y por esta razón mantendré el sentido de mi voto... ${ }^{67}$

Decimos que se trata de coherencia judicial debido a que la ministra Luna Ramos siempre ha defendido la tesis del no sometimiento del poder revisor de la Constitución a control alguno.

Ahora bien, lo verdaderamente sorprendente aconteció unos segundos después, cuando el ministro Góngora tomó la palabra para preguntarle a

65 Ibidem, p. 12.

66 Ibidem, p. 9.

67 Extracto de la versión taquigráfica de la sesión pública ordinaria del Pleno de la SCJN, celebrada el 2 de junio de 2009, con motivo de los recursos de queja 11/2008, $12 / 2008$ y $16 / 2008$, p. 10. 
la ministra Luna Ramos los siguiente: “¿cuál es la razón de su voto en contra?", ${ }^{68}$ a lo que la ministra contestó:

¡Ah!, señor. Bueno, pensé que no íbamos a abrir la discusión en ese sentido, porque desde que habíamos fallado los cuarenta y tantos asuntos que se resolvieron todos manifestamos de manera amplia el criterio que sosteníamos, si quiere que lo repita, con muchísimo gusto lo haría. ${ }^{69}$

Acto seguido, el ministro Góngora respondía que sí, ya que “...algunos señores ministros dijeron que procedía el amparo contra la reforma constitucional, pero nada más en el procedimiento legislativo, y otros en cuanto al fondo...", ${ }^{70}$ y continuaba Góngora señalando: "Usted dijo que ni en el procedimiento legislativo ni en cuanto al fondo, eso fue lo que dijo", ${ }^{71}$ a lo que la ministra respondió: "Así es señor...". ${ }^{72}$

Fue en ese momento en donde se generaba el repentino cambio de criterio, ya que el ministro Góngora concluía este diálogo con la siguiente idea:

Bueno, yo he meditado sobre eso, y viendo los problemas que se presentan he reconsiderado, creo que me equivoqué, creo que debo de votar en el sentido de que no procede el amparo ni en cuanto al fondo ni en cuanto al procedimiento legislativo; entonces, agregaré mi voto al suyo señora ministra. ${ }^{73}$

De esta forma, uno de los principales impulsores de la existencia del núcleo intangible de la Constitución y de su defensa, modificaba por completo su criterio, lo que precisamente deja ver con claridad la complejidad del tema al que nos enfrentamos. Así, el recurso de queja 11/2008 fue resuelto por mayoría de siete votos en el sentido de que debía declararse fundada la queja, y con ello, revocar el auto admisorio de la demanda de amparo planteada por Televimex, S. A. de C. V.

Es importante mencionar que la resolución antes descrita no viene a desvanecer los tímidos pasos que la SCJN había comenzado a dar en torno a la configuración de una doctrina jurisprudencial que justifica la ne-

Ibidem, p. 11.

Idem.

70 Idem.

71 Idem.

72 Idem.

73 Ibidem, p. 12. 
cesidad de someter a control constitucional los actos del poder revisor de la Constitución, ya que el sentido de la misma, obedece principalmente a que en la demanda de Televimex, S. A. de C. V., no se plantearon conceptos de violación en donde se impugnara el procedimiento de reforma constitucional, sino que más bien, se plantearon alegaciones en torno a determinados actos del Instituto Federal Electoral, así como a los artículos del Código Federal de Instituciones y Procedimientos Electorales, materia que no puede ser conocida vía amparo debido a lo establecido en el artículo 73, fracción 7 de la Ley de Amparo. ${ }^{74}$

De hecho, en el recurso de queja 12/2008, el cual fue también resuelto en la sesión del 2 de junio de 2009, se determinó — con mayoría de seis votos - que la queja era infundada, lo que significó la confirmación del auto admisorio de la demanda de amparo interpuesta por el quejoso correspondiente, toda vez que en su demanda, sí hizo valer en sus conceptos de violación, alegaciones por vicios en el procedimiento de reforma constitucional, con lo cual se ratifica el criterio que venía sosteniendo la mayoría de los ministros de la SCJN, en el sentido de que la sola presentación de demandas de amparo en contra de reformas constitucionales no actualiza el supuesto de notoria e indudable improcedencia. Pero lo verdaderamente sorprendente, y que fue precisamente lo que nos motivó a analizar este precedente, fue la forma en cómo el ministro Góngora modificó sustancialmente su criterio.

De todo lo anterior, consideramos que debemos hacer especial énfasis en que muchas de las ideas vertidas por los ministros en el sentido de reconocer la necesidad de limitar al poder constituyente permanente son trascendentes, debido a que pueden ser el punto de partida para consolidar una doctrina jurisprudencial que permita realizar un control formal de las enmiendas a la carta magna, lo cual podría generar en el futuro la idea de ejercer también un control material a partir de la identificación de ese núcleo intangible al que hacía referencia el ministro Góngora antes de su radical cambio de criterio.

74 Artículo 73. El juicio de amparo es improcedente: VII. Contra las resoluciones o declaraciones de los organismos y autoridades en materia electoral. 


\section{LAS CONCLUSIONES}

...el pueblo tiene el derecho original para establecer para su futuro gobierno, los principios que en su opinión mejor logren su propia felicidad... los principios así establecidos, se estiman fundamentales. $Y$ como la autoridad de la cual emanan es suprema y no puede obrar con frecuencia, la intención al establecerlos es de que sean permanentes... ${ }^{75}$

John MARSHALL

Sobresale que con los planteamientos vertidos durante los debates relativos a las acciones de inconstitucionalidad 168/2007-169/2007 y al amparo en revisión 186/2008, algunos de los ministros de la SCJN parecen acercarse cada vez más a doctrinas jurisprudenciales que ya han sido formuladas por otros tribunales constitucionales en Latinoamérica.

Concretamente nos referimos a la doctrina fijada en el caso Fayt, la cual

significó que, por primera vez en la historia del Estado federal argentino, la Corte Suprema de Justicia realizara un juicio de constitucionalidad con total plenitud sobre disposiciones normativas creadas por una Convención Nacional Constituyente que reformó la letra de la ley mayor. La reforma constitucional de 1994 fue y lo sigue siendo — sin dudas — la que en toda la historia constitucional de la Argentina mayor grado de legitimación democrática ha gozado. Por tanto, la nulidad de reglas constitucionales creadas por el poder constituyente, como ocurrió en Fayt, genera la reapertura del debate en torno de los fundamentos del control de constitucionalidad. ${ }^{76}$

En dicho caso, la Corte Suprema argentina señalaría en el considerando 5 que:

75 Corte Suprema de Justicia de los Estados Unidos de América, Marbury vs. Madison, 1803.

76 Ferreyra, Raúl Gustavo, "Reforma constitucional y cuestiones políticas", Revista Iberoamericana de Derecho Procesal Constitucional, núm. 7, enero-junio de 2007, p. 114, http://www.iidpc.org/revistas/7/pdf/35_56.pdf 
No obsta a lo afirmado la circunstancia de que lo atinente al contenido de una reforma constitucional haya sido atribuido válidamente a un poder distinto del Judicial, pues aun en tales hipótesis siempre este departamento, a la luz de la Constitución, está habilitado para juzgar en los casos que se le planteen, si el acto impugnado ha sido expedido por el órgano competente, dentro del marco de sus atribuciones y con arreglo a las formalidades a que está sujeto. Y, de inmediato, prosiguieron el razonamiento: el mandato de la Constitución que pesa sobre el Poder Judicial es el de descalificar todo acto que se oponga a aquélla (CSJN, Fallos: 32:120); planteada una causa, no hay otro poder por encima del de esta Corte para resolver acerca de la existencia y de los límites de las atribuciones constitucionales otorgadas a los otros poderes y del deslinde de atribuciones de estos entre sí. No admite excepciones, en esos ámbitos, el principio reiteradamente sostenido por este tribunal, desde 1864, en cuanto a que es el intérprete final de la Constitución (CSJN, Fallos: 1:340). Si la esencia de nuestro sistema de gobierno radica en la limitación de los poderes de los distintos órganos y en la supremacía de la Constitución, ningún departamento puede ejercer lícitamente otras facultades que las que le han sido acordadas (CSJN, Fallos: 137:47) y es del resorte de esta Corte juzgar la existencia y límites de las facultades privativas de los otros poderes (CSJN, Fallos: 210:1095) y la excedencia de las atribuciones en la que éstos puedan incurrir (CSJN, Fallos, 254:43). ${ }^{77}$

Tal conjunto de premisas básicas — sostiene Ferreyra — no pasaría por alto la oportunidad de cerrar con una conclusión contundente:

Incluso, en los casos en que la interpretación constitucional lleve a encontrar que determinadas decisiones han sido atribuidas con carácter final a otras "ramas del gobierno", el tribunal siempre estará habilitado para determinar si el ejercicio de una potestad de dicha naturaleza ha sido llevada a cabo, dentro de los límites de ésta y de acuerdo con los recaudos que le son anejos. El quebrantamiento de algunos de los mentados requisitos o el desborde de los límites de la atribución, harían que la potestad ejercida no fuese, entonces, la de la Constitución y allí es donde la cuestión deja de ser inmune a la revisión judicial por parte del tribunal encargado — por mandato de aquélla — de preservar la supremacía de la ley fundamental. ${ }^{78}$

Más adelante —en el considerando 7- la Corte Suprema de Justicia de Argentina recordaba “...la doctrina citada en Ríos: la facultad de re- 
formar la Constitución no puede exceder el marco de la regulación constitucional en que descansa". ${ }^{79}$

Ahora bien, independientemente del precedente argentino, podemos ver que la litis en torno a la reforma constitucional en materia electoral - o cualquier otra de similares características - no ha sido resuelta de manera definitiva, por lo que no debemos olvidar que la jurisprudencia - como fuente del derecho constitucional — es la vía más dúctil para no frenar su evolución, razón por la cual nos parece acertado que la SCJN vuelva a revisar este tema, máxime si ha cambiado su integración desde 1999 a la fecha, por lo que debe concedérseles a los nuevos ministros que no han participado en la conformación de la doctrina jurisprudencial analizada, la oportunidad de revisarla y, en su caso, consolidarla, o bien, modificarla.

Así, lo único cierto es que, hoy más que nunca, se presenta como ineludible la necesidad de transitar de la sola defensa de la Constitución, a la defensa del núcleo intangible de la misma, ya que — parafraseando al Estagirita - resulta evidente, en efecto, que podríamos diferenciar los bienes constitucionales según una doble acepción: unos por sí mismos, otros por razón de aquéllos. Separando pues, los bienes constitucionales esenciales de los bienes constitucionales útiles, distinción la cual nos obliga también a distinguir la tutela y protección que requieren, ya que los segundos dependen de los primeros, por lo que resulta más coherente con los conceptos básicos del constitucionalismo contemporáneo, pensar en que el poder constituyente constituido posea límites y, de esta forma, se reconozca la existencia de entidades jurídicas anteriores, superiores y/o exteriores al propio Estado y sus órganos, entidades las cuales, posibiliten una vivencia real bajo el imperio del derecho y que se configuren en el núcleo intangible de la Constitución.

¿Cuáles sean esos límites, cómo se definen adecuadamente y cómo deban protegerse?, son asuntos, responde Ferreyra, “...de significativa magnitud y trascendencia que requiere[n], ciertamente, un estudio específico", ${ }^{80}$ mismo que estaremos publicando con posterioridad.

Ibidem, pp. 116 y 117.

80 Ibidem, p. 124.

Fecha de recepción: 6 de noviembre de 2008.

Fecha de dictamen: 1o. de junio de 2009. 